\title{
ESCULTURAS DE CRISTÓBAL RAMOS EN LA CAPILLA DE SAN JOSÉ DE SEVILLA
}

\author{
SCULPTURES BY CRISTÓBAL RAMOS AT \\ SAINT JOSEPH CHAPEL IN SEVILLE
}

\author{
José RodA PeÑA \\ Universidad de Sevilla. España \\ roda@us.es
}

\begin{abstract}
La capilla de San José, construida en pleno corazón histórico de Sevilla como sede de la hermandad gremial de los carpinteros de lo blanco, conserva tanto en el interior de sus muros como en sus dos portadas exteriores un interesante conjunto de obras escultóricas de Cristóbal Ramos (17251799) realizadas a comienzos del último tercio del siglo XVIII, la mayoría de las cuales se le atribuyen por vez primera en este estudio.

Palabras clave: Cristóbal Ramos; escultura; siglo XVIII; capilla de San José; Sevilla.
\end{abstract}

The Saint Joseph Chapel, built in the historic heart of Seville as the seat of the guild brotherhood of carpenters, preserves both inside its walls and its two exterior fronts an interesting collection of sculptures by Cristóbal Ramos (1725-1799) made at the beginning of the last third of the $18^{\text {th }}$ century, most of which are attributed to him for the first time in this paper.

Keywords: Cristóbal Ramos; sculpture; $18^{\text {th }}$ century; Saint Joseph Chapel; Seville.

Buena parte del siglo XVIII contempla en Sevilla, y diríamos que en toda Andalucía, la prolongación de las formas artísticas barrocas, gracias al decidido apoyo de una amplia clientela que se siente plenamente identificada con las mismas y con sus planteamientos ideológicos y estéticos. Pero es bien cierto que el espíritu que alienta dichas creaciones dieciochescas es muy diferente al que sobrevolaba la centuria anterior, como distinto fue el ambiente político, religioso, social y cultural en el que aquellas se gestaron. Un elocuente síntoma de este cambio vendría protagonizado, en el plano artístico, por la renovadora aunque siempre parcial y tamizada asimilación de una serie de componentes técnicos, estilísticos y temáticos de procedencia italiana y francesa, que venían a poner de relieve la influencia ejercida por la nueva dinastía borbónica y la presencia de artistas extranjeros en la Corte y también en Sevilla, ciudad en la que estuvo residiendo Felipe 
V y su familia entre 1729 y 1733 durante el denominado Lustro Real. Por otro lado, la fundación en tierras andaluzas, durante el último tercio del Setecientos, de academias y escuelas artísticas, además de la influencia ejercida por las Sociedades Económicas de Amigos del País, hizo factible la convivencia del barroco tradicional con las innovadoras corrientes estéticas de signo ilustrado que apelaban al "buen gusto" clasicista.

En este contexto hay que insertar la figura del escultor sevillano Cristóbal Ramos (1725-1799), activo profesionalmente durante la segunda mitad del siglo XVIII, quien desde unos iniciales presupuestos tardobarrocos de influencia rococó, supo evolucionar hacia recursos compositivos y formales que acusan la influencia del clasicismo academicista. Él se había formado junto a su padre, el barrista Juan Isidoro Ramos ( $\uparrow 1787)$, con quien dominó la técnica del modelado en este material, hasta convertirlo en el predominante en su producción -hasta el punto de que algún coetáneo se refirió a él como "escultor en barro, y no en madera"-, junto a las telas encoladas y la pasta. Vinculado, desde su fundación, a la Real Escuela de las Tres Nobles Artes, allí desempeñó desde 1775 hasta su muerte en 1799 el cargo de teniente de escultura, al tiempo que su colega el valenciano Blas Molner y Zamora (1738-1812) dirigía dicha sección. Entre sus discípulos directos destacaron su propio sobrino Cesario Ramos (1768-1850) y el afamado Juan de Astorga (1777-1849). Su producción, muy extensa cuantitativamente y en registros temáticos, gozó de un amplio reconocimiento social, estando repartida fundamentalmente por las actuales provincias de Sevilla, Huelva, Cádiz y Córdoba ${ }^{1}$.

${ }^{1}$ De imprescindible consulta es la única monografía publicada sobre este artista, debida a MONTESINOS MONTESINOS, Carmen: El escultor sevillano D. Cristóbal Ramos (1725-1799). Sevilla, 1986. La bibliografía principal generada con posterioridad en torno a la producción de dicho escultor aparece anotada en RODA PEÑA, José: "Escultura en la Baja Andalucía durante el siglo XVIII: síntesis interpretativa e historiografía reciente", Mirabilia Ars, 1, 2014, pp. 179-180. Las aportaciones más recientes a su catálogo las podemos encontrar en DOBADO FERNÁNDEZ, Juan: "Iconografía de Teresa de Jesús en Sevilla: la Santa escritora y la Transverberación", en Una mujer de Dios: Santa Teresa y Sevilla, cat. exp. Sevilla, 2015, pp. 11-12; DOBADO FERNÁNDEZ, Juan: "Obras firmadas y atribuciones de Santa Teresa”, Miriam, 394, 2015, pp. 134-135; RODA PEÑA, José: "La iconografía de Santa Ana enseñando a leer a la Virgen y sus modelos escultóricos en la Sevilla del Barroco", en El joven Velázquez. A propósito de La Educación de la Virgen de Yale. Sevilla, 2015, pp. 457-459; DOBADO FERNÁNDEZ, Juan: "Biblioteca-Museo Mariano de Sevilla. Nuevas Atribuciones", Miriam, 398, 2016, p. 57; RODA PEÑA, José: "Imágenes de devoción en la parroquia de Santa Ana", en RODRÍGUEZ BABÍO, Amparo (ed. y coord.): Santa Ana de Triana: Aparato histórico-artístico. Sevilla, 2016, pp. 444 y 449-450; MARTÍNEZ LARA, Pedro Manuel y DE LA TORRE AMERIGHI, Iván: "Una escultura desconocida de Cristóbal Ramos (1725-1799). Iconografía, uso artístico y mentalidad ilustrada a propósito de una imagen de San José con Niño", Liño, 23, 2017, pp. 57-68; y MORENO 
En el transcurso del presente trabajo, pretendemos incrementar el catálogo de las obras atribuidas a Cristóbal Ramos, con varios grupos escultóricos que se localizan en la capilla de San José, una de las joyas de la arquitectura barroca sevillana -declarada Monumento Nacional en 1912-, que un día perteneciera a la hermandad y gremio de carpinteros de lo blanco que tenían como titular al patriarca bendito, y cuyo culto regentan desde 1916 los hermanos menores capuchinos, a quienes les sería cedida su propiedad en $1964^{2}$.

Como es sabido, el incendio provocado en la noche del 11 al 12 de mayo de 1931 infligió graves daños tanto al inmueble, enclavado en pleno corazón histórico de la ciudad, como al valioso patrimonio documental y artístico que atesoraba su interior, en cuya rehabilitación, comenzada de inmediato al nefasto suceso $^{3}$, aún se sigue trabajando afanosamente.

Precisamente, en aquel siniestro quedó destruido el diminuto Niño Jesús de cuna que formaba parte de un Nacimiento que indiscutiblemente pertenecía en su integridad original a la mano de Cristóbal Ramos (Figura 1), siendo sustituido por otra efigie infantil que, dadas sus características morfológicas y rasgos faciales, pensamos que debió de ser esculpida por Sebastián Santos Rojas (1895-1977), cuya estrecha vinculación con la comunidad capuchina de Sevilla resulta bien conocida ${ }^{4}$. Según nos revela fray Diego de Valencina (1862-1950) ${ }^{5}$, que vivió en pri-

ARANA, José Manuel: "Tres nuevas obras del escultor Cristóbal Ramos", Laboratorio de Arte, 29, 2017, pp. 819-826.

${ }^{2}$ Una rigurosa síntesis sobre la historia de esta hermandad gremial, el proceso constructivo de su capilla y el patrimonio artístico custodiado en su interior la encontramos en CRUZ ISIDORO, Fernando: La capilla de San José del gremio de carpinteros de lo blanco. Sevilla, 2015.

${ }^{3}$ DE VALENCINA, P. Diego: El incendio de la Capilla de San José. Sevilla, 1939, p. 32; y RODRÍGUEZ CONDE, Raquel: "El patrimonio documental capuchino en la capilla de San José y el incendio del 12 de mayo de 1931", en VALIENTE ROMERO, Antonio (coord.): Los Capuchinos y la capilla de San José: un siglo de convivencia (1916-2016). Sevilla, 2016, pp. 115-191.

${ }^{4}$ SANTOS CALERO, Sebastián: Sebastián Santos Rojas. Escultor-Imaginero. Sevi1la, 1996, pp. 29-30.

${ }_{5}$ Nacido en Valencina de la Concepción (Sevilla), fue numerario de la Real Academia Sevillana de Buenas Letras y correspondiente de la Real Academia de Bellas Artes de San Fernando de Madrid, así como un reconocido experto en la obra literaria de Fernán Caballero y en el estudio histórico del cante por saetas. En varias ocasiones fue elegido guardián del convento de Sevilla y superior de la capilla de San José, así como de los cenobios de Sanlúcar de Barrameda y Córdoba, desempeñando también los cargos de maestro de novicios, custodio general y ministro provincial de Andalucía. Véase la reseña necrológica que le dedicó el diario $A B C$ de Sevilla, el 15 de abril de 1950, p. 10 y el bien documentado trabajo de GALBARRO GARCÍA, Jaime: "Fray Diego de Valencina y la actividad cultural de la capilla de San José", en VALIENTE ROMERO, Antonio (coord.): Los Capuchinos y la capilla de San José: un siglo de convivencia (1916-2016). Sevilla, 2016, pp. 77-113. 
mera persona el nefasto incendio y coordinó las primeras tareas restauradoras de la capilla, la Virgen de aquel conjunto quedó rota, pero pudo recomponerse sin mayores problemas, mientras que la imagen de San José hubo que rehacerla de nuevo, "tomando por base lo poco que queda[ba] de la otra" ${ }^{6}$, tareas en las que probablemente también estuvo implicado Sebastián Santos. El erudito capuchino ya nos informaba de que tales esculturas "eran de barro cocido policromado, atribuidas a Cristóbal Ramos" eco el profesor Cruz Isidoro, "por comparación de gestos y actitudes con el [Nacimiento] conservado en colección particular de Lebrija" ". Creo que dicho ejercicio comparativo solo puede acometerse, en puridad, con la imagen en terracota y telas encoladas de la Virgen, la menos alterada del elenco -frente al nuevo Niño Jesús de Sebastián Santos y al muy rehecho San José- que, efectivamente, cabe relacionar de manera directa con la representación mariana del misterio navideño que obra en poder de la familia Cortines en Lebrija ${ }^{9}$ - por sus idénticos materiales constitutivos, mismo tipo facial juvenil y sonriente, equivalente disposición arrodillada con el torso inclinado, y parejos ademanes de arrobo y adoración de sus respectivas cabezas y manos, expresivamente dirigidos hacia el pequeño Infante-, y aun con ciertos distingos advertidos en la composición de sus pliegues indumentarios, también puede esgrimirse un paralelismo similar con las Vírgenes de los Nacimientos que en la capital hispalense poseen los padres filipenses de San Alberto $^{10}$ y las monjas jerónimas de Santa Paula ${ }^{11}$, entre otros ejemplos más que podrían aducirse.

Este Nacimiento de la capillita de San José se exhibe en una vitrina, inserta a la derecha del retablo-tribuna que, en el lado de la epístola del transepto, sirve al mismo tiempo de portada para el tránsito a la sacristía del recinto. De tipología rococó, se desconoce quién pudo ser el autor del diseño y talla de este dispositivo arquitectónico, concebido -como apunta el profesor Recio Mir-con un

${ }^{6}$ DE VALENCINA, P. Diego: El incendio de la Capilla de San José, op. cit., p. 28. En nota a pie de página menciona que "A estas horas ya está restaurada [la Virgen], y haciéndose la de San José".

${ }^{7}$ Ibidem.

${ }^{8}$ CRUZ ISIDORO, Fernando: La capilla de San José..., op. cit., p. 132.

${ }_{9}$ MONTESINOS MONTESINOS, Carmen: El escultor sevillano..., op. cit., pp. 36 y 76. Está firmado por Cristóbal Ramos en la base de la mula.

${ }^{10}$ Ibidem, p. 36. MARTÍN RIEGO, Manuel y RODA PEÑA, José: El Oratorio de San Felipe Neri de Sevilla. Historia y Patrimonio Artístico. Córdoba, 2004, p. 496.

${ }^{11}$ MONTESINOS MONTESINOS, Carmen: El escultor sevillano..., op. cit., p. 36; y RODA PEÑA, José: "Nacimiento. Cristóbal Ramos", en FALCÓN MÁRQUEZ, Teodoro (com.): La ciudad oculta. El universo de las clausuras de Sevilla, cat. exp. Sevilla, 2009, pp. 206-207. 
sentido más aditivo que tectónico, fechándose hacia $1765^{12}$ y encargándose los maestros Juan Mateos del Parque, Vicente Alanís y Francisco José Morales Fariñas de su dorado y estofado entre 1777 y $1779^{13}$. Creo que ese marco cronológico de la década de 1770 se ajustaría bastante bien con la posible datación de este Nacimiento de Cristóbal Ramos y con el del otro grupo, asimismo de pequeño formato y modelado también en terracota y telas encoladas, que consideramos como obra indudable de su mano, y que se encuentra situado justamente frontero al anterior, en una hornacina del retablo-tribuna del lado del evangelio del crucero, representando el Tránsito de San José asistido por Cristo y María (Figura 2).

En un inventario de 1933 ya aparecía esta escena de la Gloriosa Muerte de San José atribuida a Cristóbal Ramos ${ }^{14}$. Este parece haberse inspirado a la hora de componer iconográficamente el conjunto, tan inusual en la plástica escultórica sevillana, en un conocido pasaje de la apócrifa Historia copta de José el Carpintero, extraído de su capítulo diecinueve, donde Cristo narra en primera persona: "Yo, ¡oh mis amigos!, me senté a su cabecera, y María, mi madre, a sus pies. Él levantó los ojos hacia mi rostro. Y no pudo hablar, porque el momento de la muerte lo dominaba. Entonces alzó otra vez la vista, y lanzó un gran gemido. Yo sostuve sus manos y sus pies un largo trecho, mientras él me miraba y me imploraba, diciendo: No dejéis que me lleven. Yo coloqué mi mano en su corazón, y conocí que su alma había subido ya a su garganta, para ser arrancada de su cuerpo. No había llegado aún el instante postrero, en que la muerte debía venir, porque, si no, ya no hubiera aguardado más. Pero habían llegado ya la turbación y las lágrimas que la preceden" ${ }^{15}$. Al igual que en este expresivo fragmento literario, tres son los protagonistas de la presea escultórica, y en todos ellos se percibe con claridad la delicadeza gestual propia del quehacer de Ramos y la plasmación de las fisonomías más habituales en su producción autógrafa. Aparece Jesús, que se inclina amo-

${ }^{12}$ RECIO MIR, Álvaro: "Retablo-tribuna-portada de la sacristía", en HALCÓN, Fátima; HERRERA, Francisco y RECIO, Álvaro: El retablo barroco sevillano. Sevilla, 2000, p. 264; y RECIO MIR, Álvaro: "El brillante final del barroco: el retablo rococó", en HALCÓN, Fátima; HERRERA, Francisco y RECIO, Álvaro: El retablo sevillano. Desde sus orígenes a la actualidad. Sevilla, 2009, p. 357.

${ }^{13}$ CABEZAS GARCÍA, Álvaro: Vicente Alanís (1730-1807). Sevilla, 2011, pp. 68-69 y 98. Transcribe la documentación este mismo autor en Teoría del gusto y práctica de la pintura en Sevilla (1749-1835). Sevilla, 2015, pp. 428-431.

${ }^{14}$ Así lo recoge CRUZ ISIDORO, Fernando: La capilla de San José..., op. cit., p. 131.

15 Los evangelios apócrifos. Ed. crítica de A. Santos Otero. Madrid, 2004, p. 177. Un estudio iconográfico de este grupo escultórico, aun desconociendo su autoría y fechándolo erróneamente en la primera mitad del siglo XVIII, lo ofrece FLORES GARCÍA, Francisco José: "La Gloriosa Muerte de San José de la Capilla del Gremio de Carpinteros de Sevilla", en Primer Simposio Nacional de Imaginería. Actas. Sevilla, 1995, pp. 141-149. Más información sobre este tema iconográfico en DE ARRIBA CANTERO, Sandra: Arte e Iconografía de San José en España. Valladolid, 2013, pp. 107-110. 
rosamente sobre el lecho donde yace su anciano padre agonizante, a quien sostiene la testa para musitar junto a su oído palabras consoladoras en este convulso trance hacia la vida eterna; y en pie, junto a la cabecera del moribundo, su esposa María, que llora amargamente, derramando abundantes lágrimas que seca en un largo pañuelo que sostiene en su mano derecha, al tiempo que con la izquierda se recoge el manto que, cayendo desde su cabeza, se tercia en diagonal por el frente de la figura.

Seguidamente, me propongo atribuir por primera vez a Cristóbal Ramos la decoración escultórica de las dos portadas de esta misma capillita de San José, esto es, tanto la principal que se abre a los pies de este templo, como la lateral que permite el acceso desde el lado del evangelio, dando ambas a la calle Jovellanos. Lo primero que desearía es deshacer un grave error, pues la figura de San José con el Niño Jesús en brazos (Figura 3) que preside la referida portada principal no es, como supuso Antonio Sancho Corbacho y después ha venido repitiendo la historiografía artística local hasta hoy, una estatua de piedra cuyo dibujo hiciera en 1716 Lucas Valdés y esculpiera al año siguiente "un tal" Juan de Dios ${ }^{16}$, sino que se trata de una efigie en barro cocido sin policromar -como el resto del programa escultórico- que responde con claridad a las características de la obra de Cristóbal Ramos, como lo anuncia el propio tipo físico del santo, tan similar al del hospital de la Santa Caridad (1782) ${ }^{17}$, por citar un solo ejemplo. Esa misma identidad con los rasgos formales y expresivos que aparecen codificados en la plástica de Ramos la reconocemos en el cúmulo de nubes con cabezas aladas de ángeles en altorrelieve que rodea a San José en el interior de la amplia hornacina de remate trilobulado que lo cobija, con la paloma del Espíritu Santo desplegando sus alas en todo lo alto.

Esta portada de los pies, de ladrillo en limpio y con azulejos blancos tapizando las zonas de fondo, se compone de un cuerpo con sendas pilastras toscanas cajeadas en los extremos, al tiempo que el vano adintelado de entrada queda escoltado por dos nichos surmontados por cartelas de perfiles arrocallados con inclusión de flores y de una testa angélica en sus respectivos coronamientos. En el campo de las citadas tarjas campean estas dos inscripciones: "Por Esta Escala/ Mística de Jacob baxa/ Dios a la Tierra" y "Y los/ Hombres Su-/ben a el Cielo". En los referidos huecos se cobijaban las esculturas de pequeño formato de San Joaquín y de un santo militar que quizás pudiera identificarse con San Teodoro de Amasea, cuyos originales, para preservarlos de ataques vandálicos e intentos

${ }^{16}$ SANCHO CORBACHO, Antonio: Arquitectura barroca sevillana del siglo XVIII. Madrid, 1952, p. 134; y CRUZ ISIDORO, Fernando: La capilla de San José del gremio de carpinteros de lo blanco..., op. cit., pp. 114 y 117. Piensa este último, con razón, que pudiera tratarse del arquitecto de retablos y escultor Juan de Dios Moreno.

${ }^{17}$ RODA PEÑA, José: “Cristóbal Ramos. San José. 1782”, en Miguel Mañara. Espiritualidad y arte en el Barroco sevillano (1627-1679), cat. exp. Sevilla, 2010, pp. 232-233. 
de robo, han quedado recientemente depositados en la sacristía de la capilla, viéndose sustituidos en el exterior por una copia del primero y una Santa Ana con la Virgen Niña, modeladas ambas por el imaginero sevillano Jesús Curquejo Muri$1 \mathrm{lo}^{18}$. Frente al escaso interés artístico del presunto San Teodoro, de autoría anónima, el San Joaquín es una excelente pieza de Cristóbal Ramos, donde el padre de la Virgen - un venerable anciano tocado con turbante y sujetando un cordero en la mano izquierda- ha quedado plasmado en una versión prácticamente gemela, desde el punto de vista compositivo e iconográfico, a la empleada por el propio escultor en la imagen que modeló en terracota y telas encoladas por encargo del canónigo Pedro José del Campo para la capilla de la Virgen de la Estrella de la catedral hispalense, donde quedó entronizada, junto a una Santa Ana, que también se conserva, y un San José, ya desaparecido, el 28 de enero de $1793^{19}$. Por su parte, en el coronamiento de la portada se encajan tres medallones ovalados conteniendo santos de medio cuerpo en altorrelieve, esculpidos también en barro por Ramos. El situado por encima de la hornacina de San José representa a un San Juan Bautista (Figura 4) de fisonomía adolescente, que señala con el índice de su diestra al cordero con la cruz triunfal que sujeta en el brazo contrario; los rasgos idealizados de su rostro no están muy alejados de los de muchas de sus creaciones marianas. Sobre los fragmentos de frontón curvo que recogen lateralmente el referido ático por su base, hallamos los otros dos bustos enmarcados por paneles de perfiles mixtilíneos en los que reposan sendas parejas de angelitos -uno de ellos se ha perdido-, muy en el tipo de Ramos, como también lo están los propios santos: San Hermenegildo (Figura 5) y San Fernando (Figura 6), monarcas muy vinculados a la historia de Sevilla, habitualmente emparejados en multitud de empresas artísticas de la ciudad, que aquí comparecen acompañados de sus respectivos signos de realeza y símbolos parlantes, esto es, el hacha sobre la cabeza y la cruz en la mano izquierda en el caso del joven mártir visigodo, y la espada y la bola del mundo que porta el venerado reconquistador de la urbe. Dado que Justino Matute, en sus Anales, ofrece la fecha de 1766 como la de la terminación de esta portada, me parece lógicamente también una cronología plausible para datar toda esta decoración escultórica ${ }^{20}$.

${ }^{18}$ Este mismo escultor es el autor del Crucificado del Perdón que desde 2001 recibe culto en la propia capilla de San José. Vid. GARCÍA OLLOQUI, María Victoria: "Nuevas obras y restauraciones de Jesús Curquejo en la Capillita de San José de Sevilla”, Espacio y Tiempo: Revista de Ciencias Humanas, 16, 2002, pp. 101-109.

19 MONTESINOS MONTESINOS, Carmen: El escultor sevillano..., op. cit., pp. 48 y 116-117. Actualmente, las figuras de San Joaquín y Santa Ana de la catedral se encuentran en el altar de la Virgen de Belén.

${ }^{20}$ MATUTE Y GAVIRIA, Justino: Anales eclesiásticos y seculares de la Muy Noble y Muy Leal Ciudad de Sevilla. T. II. Sevilla, 1887, p. 217. 
No muy lejos de ese año referencial debe de situarse, en nuestro modesto criterio, la construcción de la portada lateral ${ }^{21}$, en el muro del evangelio, delatando su articulación plana y determinados elementos de su traza -el cajeado de las pilastras, la hornacina trilobulada del ático-su parentesco con la de los pies, aunque aquí en clave más sencilla, sustituyéndose el ladrillo en limpio y la azulejería por el mortero de cal, permaneciendo, eso sí, la bicromía almagra y blanca, gracias a la pintura de ambos colores que cubre, respectivamente, la molduración tectónica y las superficies de fondo. En este caso, el programa escultórico en barro cocido y sin policromar que asignamos a Cristóbal Ramos se concentra en el ático (Figura 7), teniendo como gran protagonista a la escena en altorrelieve de los Desposorios de la Virgen con San José que ocupa la referida hornacina central. Como se sabe, se trata de un pasaje respaldado de modo implícito por dos de los evangelios canónicos (Mateo y Lucas), encontrando una explícita apoyatura literaria en cuatro textos apócrifos: el Protoevangelio de Santiago, el Evangelio del Pseudo Mateo, el Libro sobre la Natividad de María y la Historia de San José el Carpintero, y con mayor extensión narrativa aún, en la Leyenda dorada de Santiago de la Vorágine y en el Speculum historiale de Vicente de Beauvais, siendo objeto de una fecunda iconografía desde comienzos del siglo XIV ${ }^{22}$. Cristóbal Ramos ha dividido la representación en dos registros: en el plano terrenal, el sumo sacerdote hebreo del templo se sitúa en el centro, bendiciendo el enlace entre San José y la Virgen, quienes extienden sus respectivos brazos derechos para cogerse de la mano como signo cardinal de su alianza matrimonial -se ha perdido la vara florecida de almendro que el patriarca sujetaría en la izquierda-, mientras en los extremos laterales, respaldando a los esposos en perfecto alineamiento isocefálico, se sitúa una pareja de varones y otra de doncellas, testigos del acontecimiento, que conversan entre sí, todo ello ante un fondo liso y neutro; en las alturas se abre un rompimiento de gloria, de relampagueante dinamismo, con un Dios Padre complacido que aparece reclinado sobre un cúmulo de nubes, acompañado por la paloma del Espíritu Santo y de una numerosa concurrencia de angelitos, algunos de los cuales recogen el aparatoso vuelo de su manto (Figura 8). Recostadas sobre fragmentos curvos de la cornisa mixtilínea con que se corona este ático, se muestran, una vez más en altorrelieves de barro cocido en su color, las figuras de San Pedro -acéfalo y portando las llaves del cielo y un libro cerrado- y San Pablo - con un libro abierto bajo la mano izquierda, careciendo de la diestra- en el plano inferior, y más arriba tenemos las representaciones alegóricas femeninas de dos de las virtudes que adornaron a San José, una de las cuales,

${ }^{21}$ El profesor Fernando Cruz piensa, en cambio, que su factura "debe ser del primer cuarto del siglo XVIII". CRUZ ISIDORO, Fernando: La capilla de San José del gremio de carpinteros de lo blanco..., op. cit., p. 114.

${ }^{22}$ CARMONA MUELA, Juan: Iconografía cristiana: Guía básica para estudiantes. Madrid, 2008, p. 137. 
al llevar un cordero en su brazo derecho, pudiera identificarse con la Castidad o la Mansedumbre -pues es símbolo de ambas-, y la otra, con la cabeza baja y los brazos cruzados sobre el pecho, quizás sea la Humildad.

Fecha de recepción: 27 de octubre de 2017

Fecha de aceptación: 30 de enero de 2018 


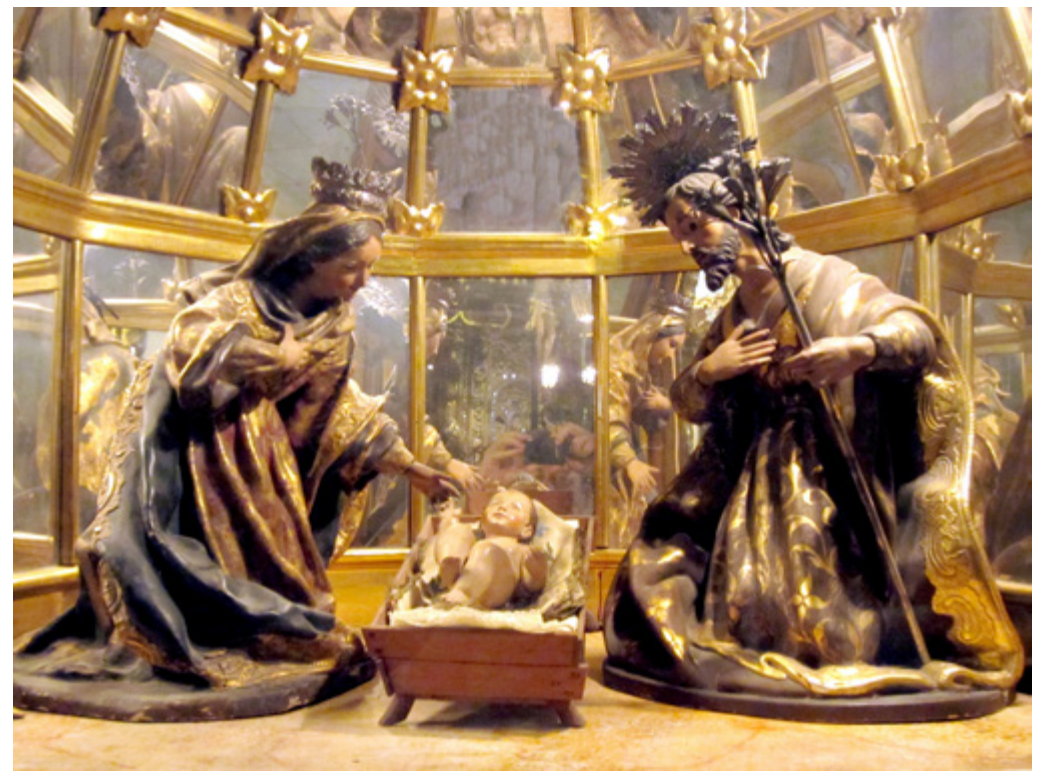

Figura 1. Cristóbal Ramos y Sebastián Santos Rojas (Niño Jesús), Nacimiento, década de 1770, capilla de San José, Sevilla.

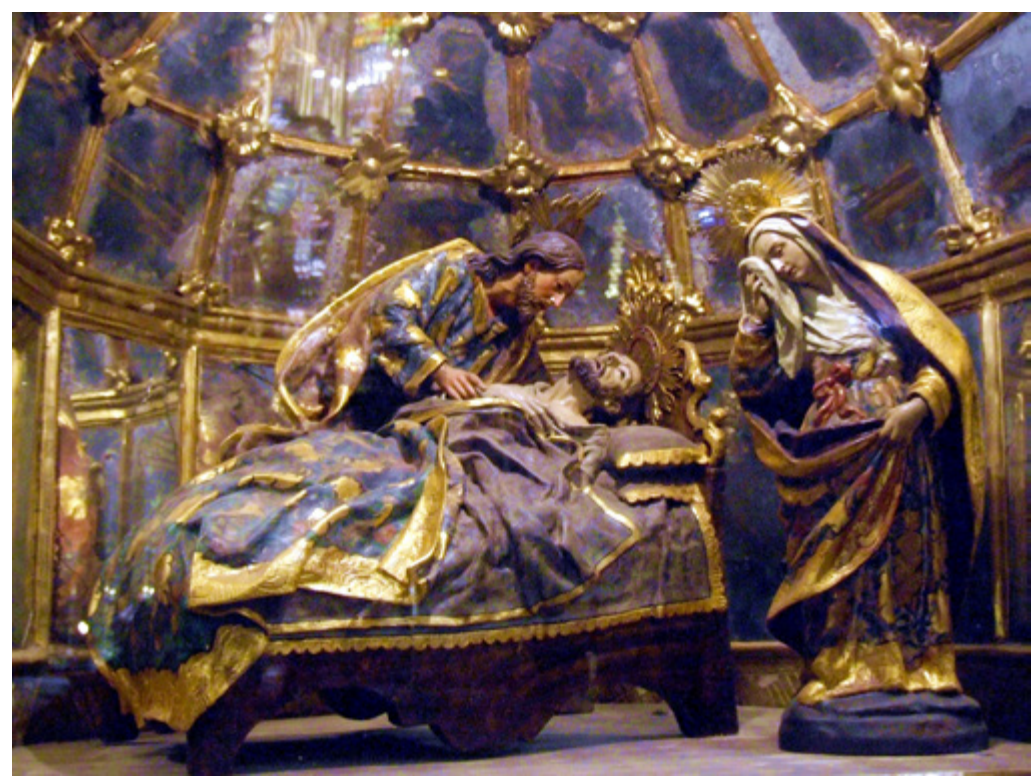

Figura 2. Cristóbal Ramos, Gloriosa Muerte de San José, década de 1770, capilla de San José, Sevilla. 


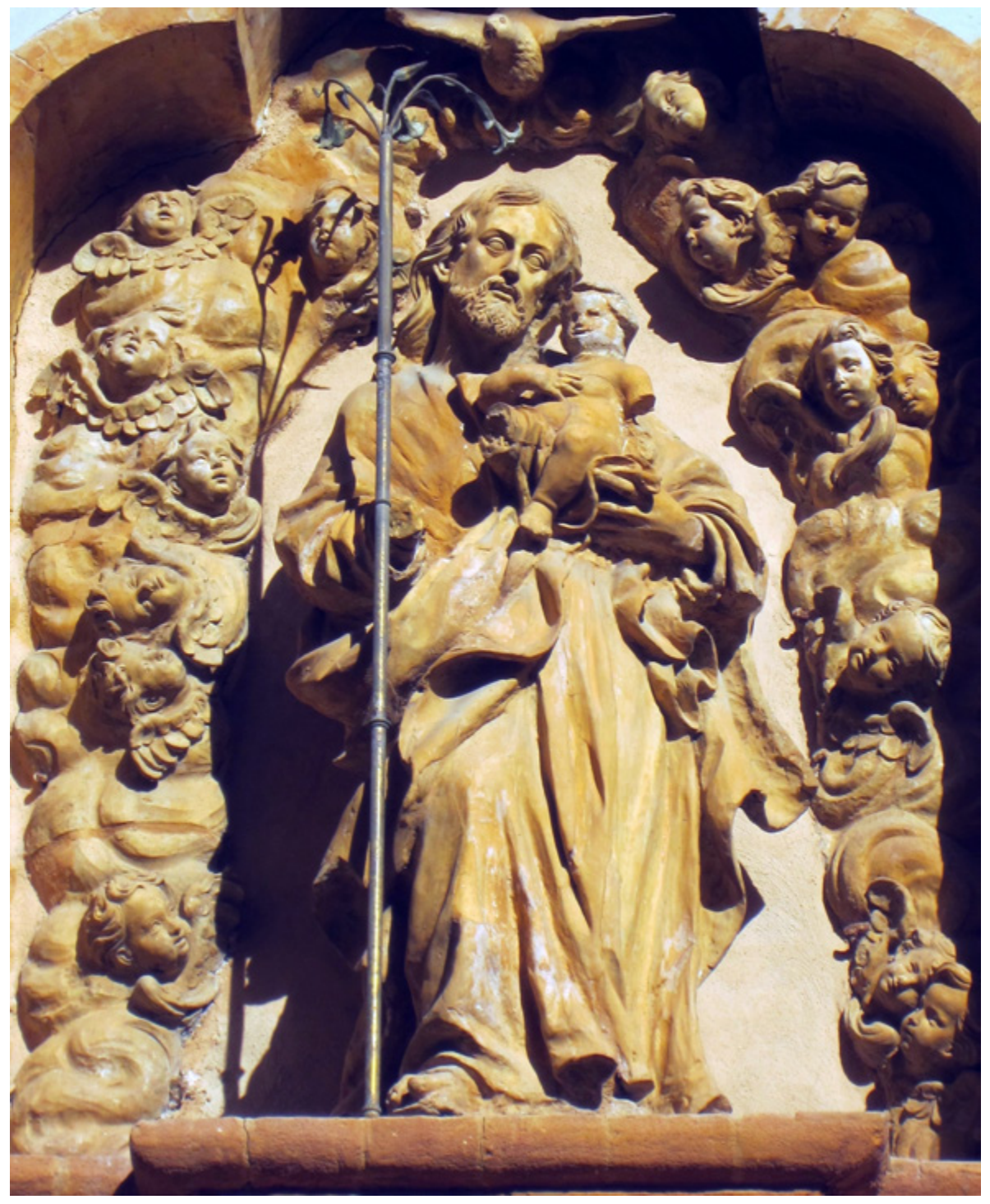

Figura 3. Cristóbal Ramos, San José con el Niño Jesús, hacia 1766, portada de los pies de la capilla de San José, Sevilla. 


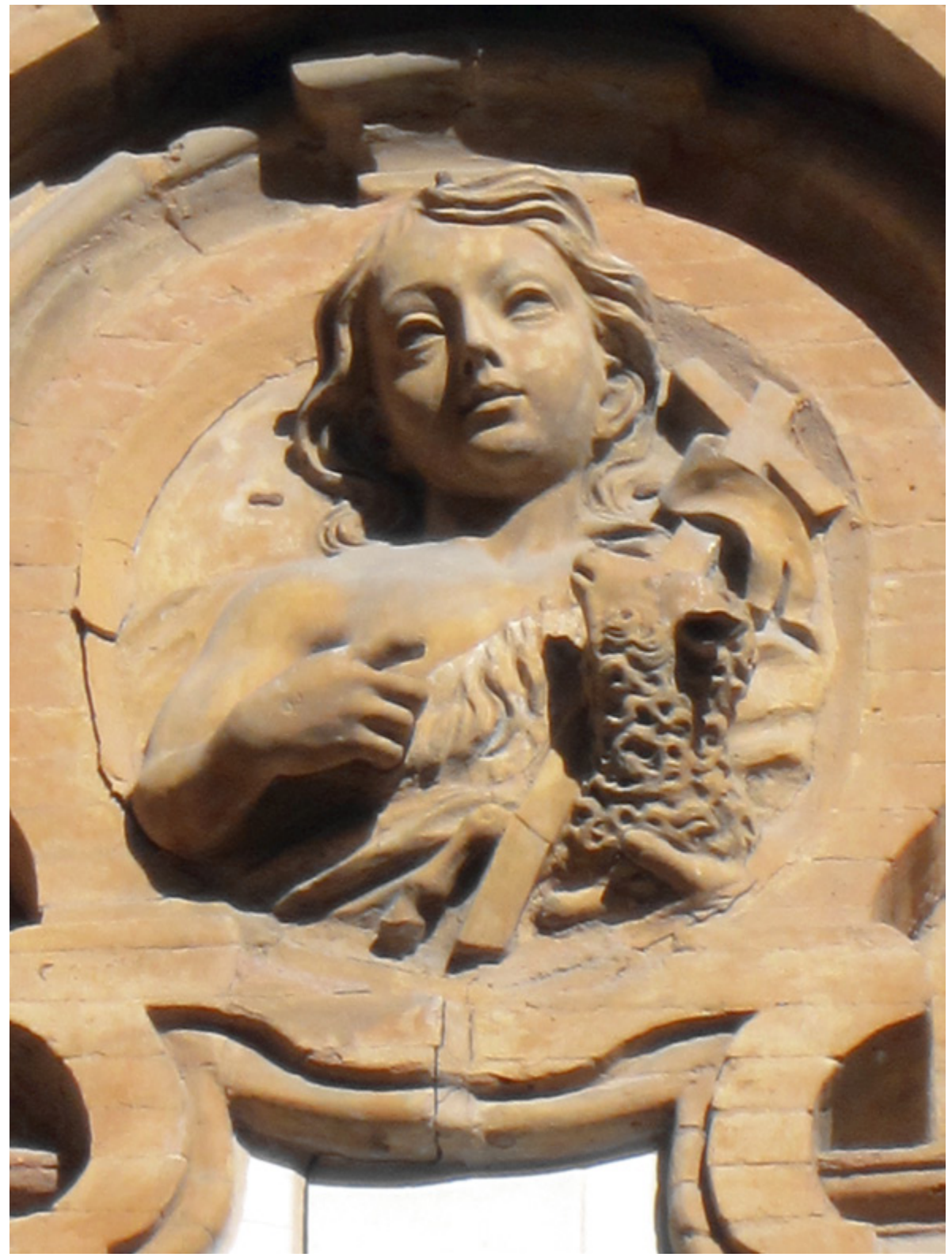

Figura 4. Cristóbal Ramos, San Juan Bautista, hacia 1766, portada de los pies de la capilla de San José, Sevilla. 


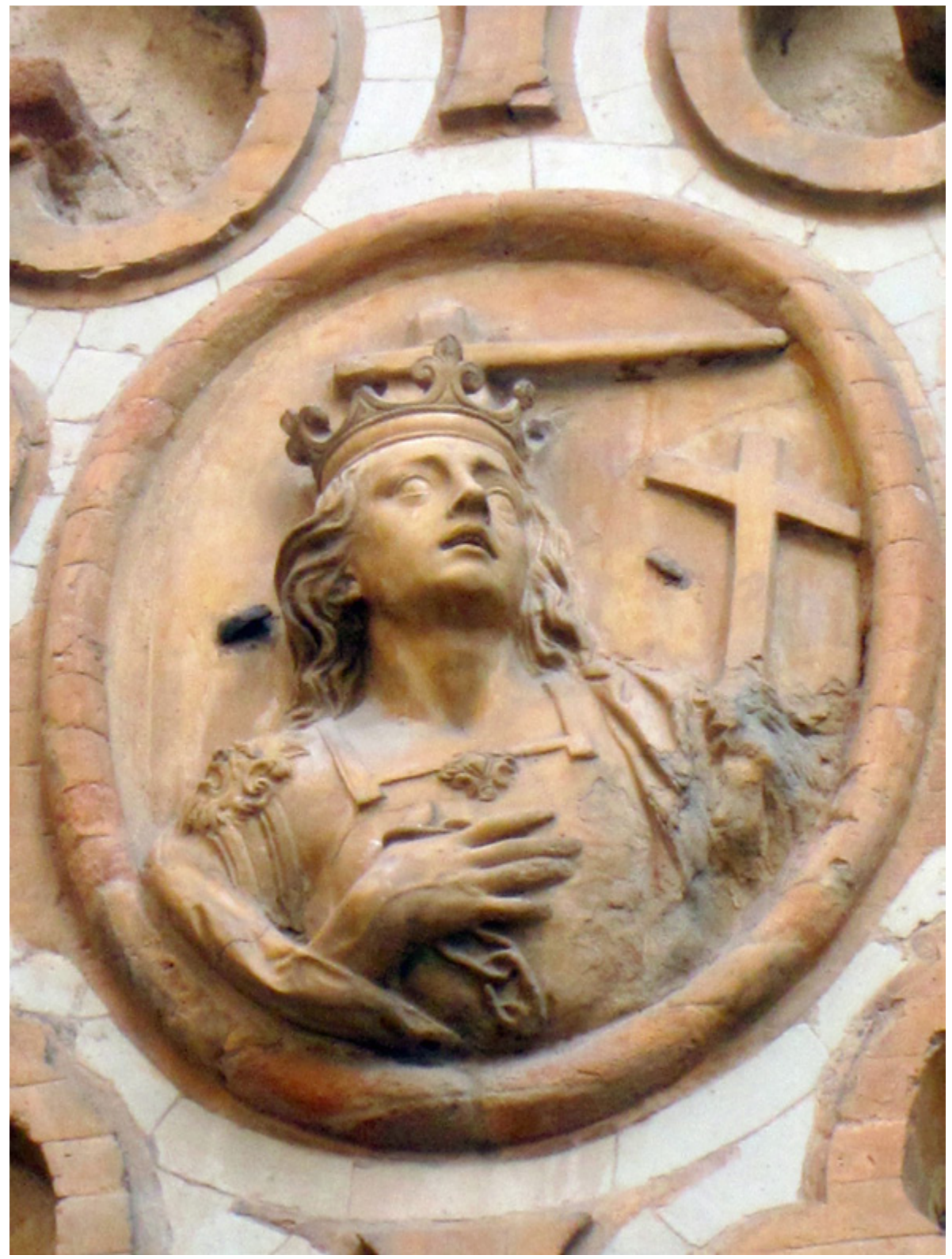

Figura 5. Cristóbal Ramos, San Hermenegildo, hacia 1766, portada de los pies de la capilla de San José, Sevilla. 


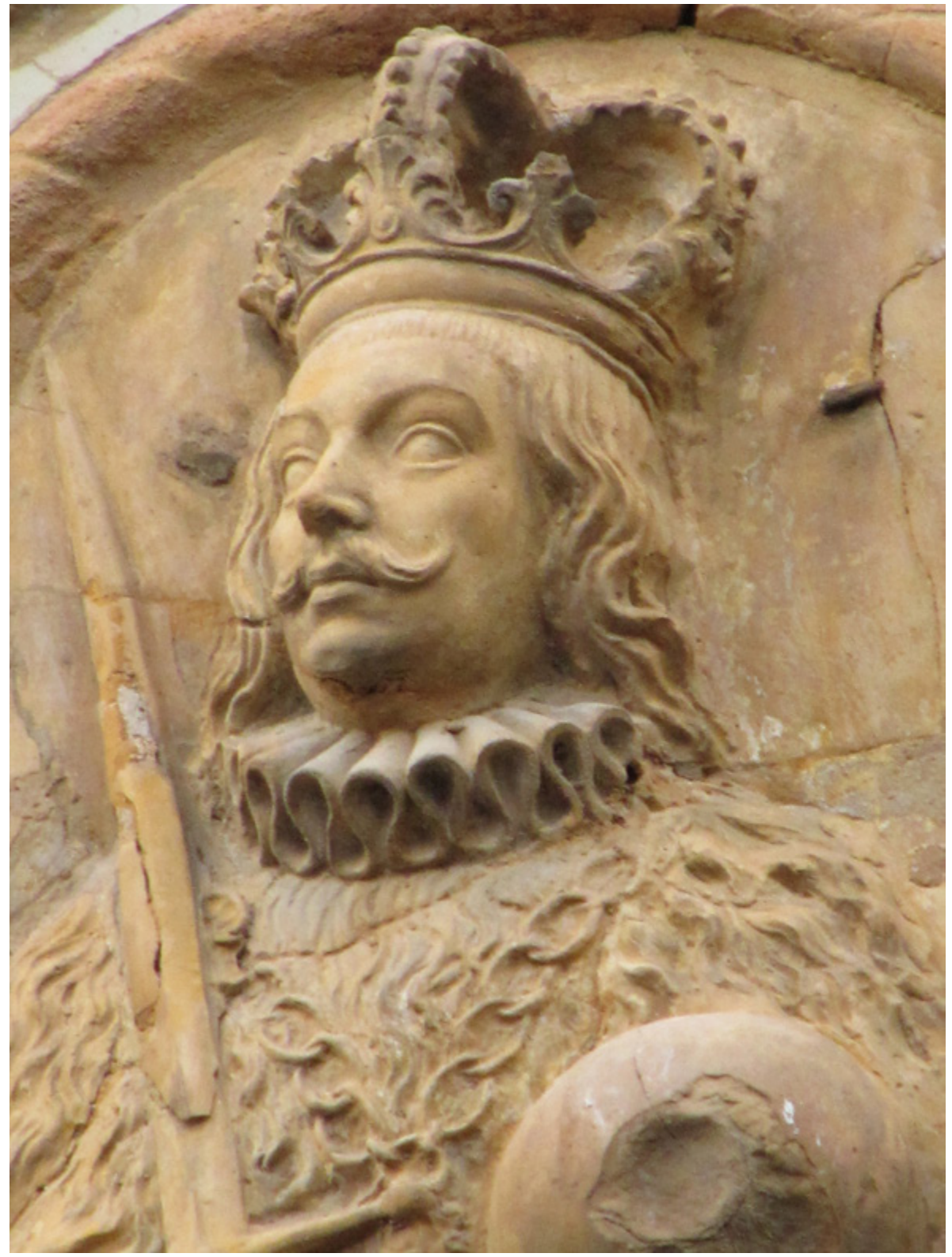

Figura 6. Cristóbal Ramos, San Fernando, hacia 1766, portada de los pies de la capilla de San José, Sevilla. 


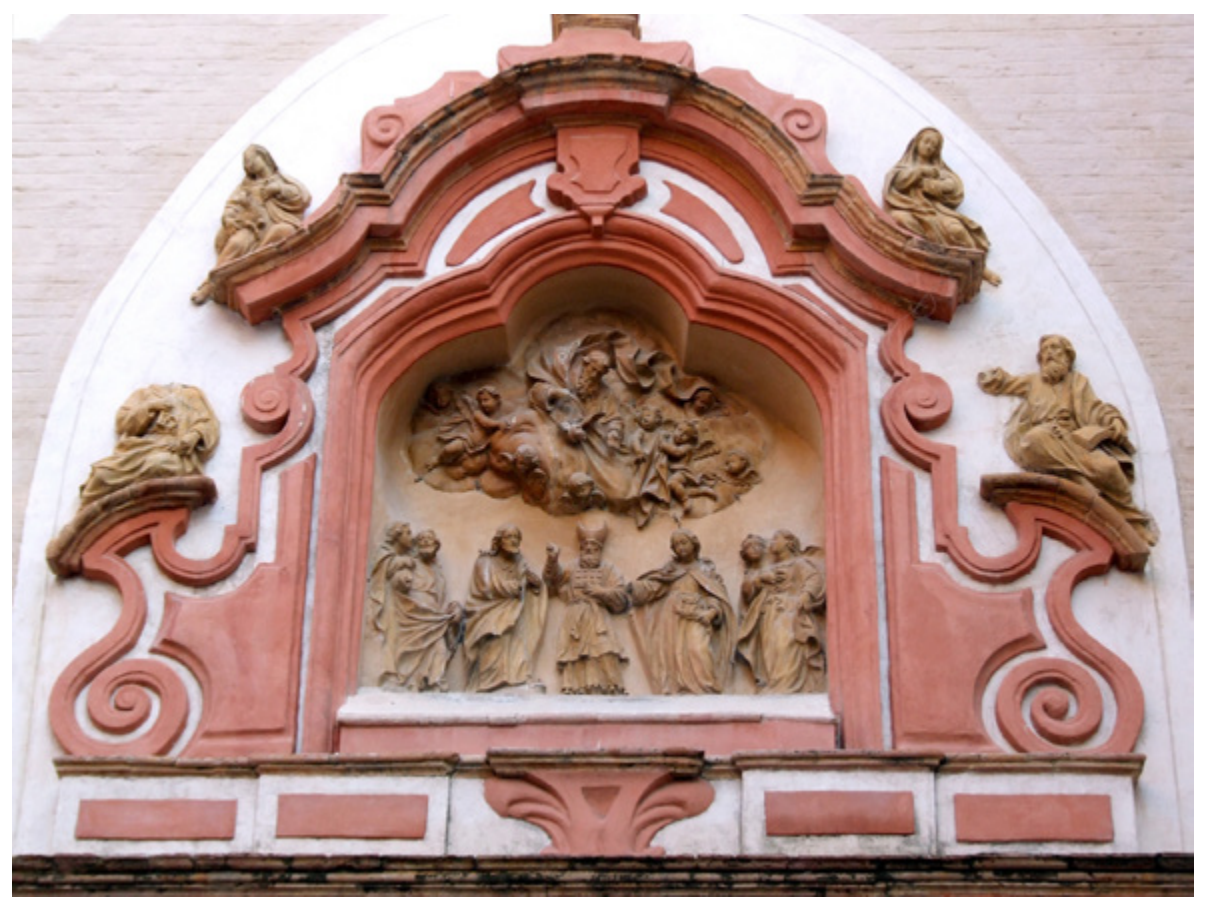

Figura 7. Cristóbal Ramos, Programa escultórico de la portada del lado del evangelio, hacia 1765-1770, capilla de San José, Sevilla. 


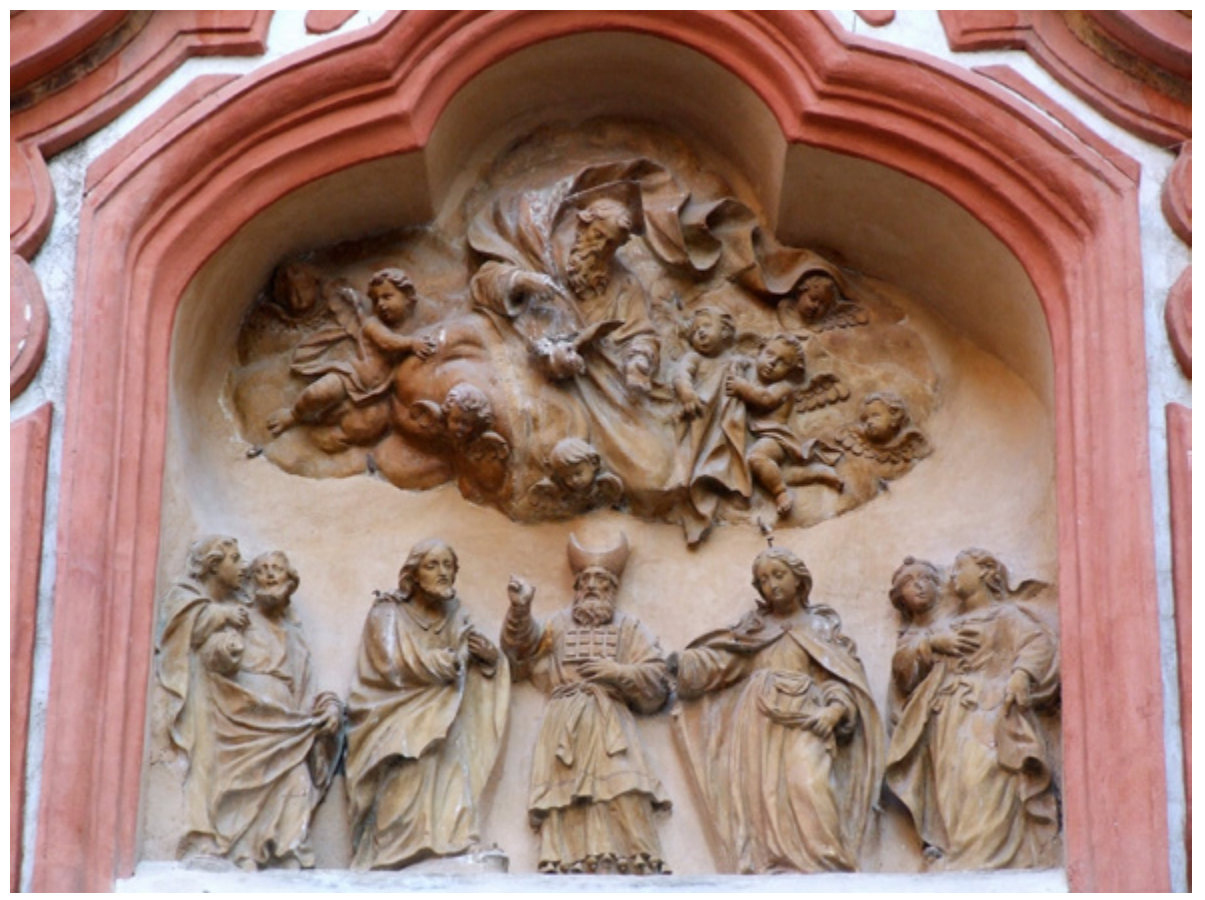

Figura 8. Cristóbal Ramos, Desposorios de la Virgen con San José, portada del lado del evangelio de la capilla de San José, Sevilla. 